\title{
The Nicaraguan Health and Demographic Surveillance Site, HDSS-León: A platform for public health research
}

\author{
RODOLFO PEÑA ${ }^{1}$, WILTON PÉREZ ${ }^{1}$, MARLON MELÉNDEZ $^{1}$, CARINA KÄLLESTÅL ${ }^{1,2} \&$ \\ LARS-ÅKE PERSSON ${ }^{2}$ \\ ${ }^{1}$ Centro de Investigación en Demografía y Salud (CIDS), UNAN-León, Nicaragua, and ${ }^{2}$ International Maternal and Child \\ Health, Department of Women's and Children's Health, Uppsala University, University Hospital, Uppsala, Sweden
}

\begin{abstract}
Aim: To describe the Health and Demographic Surveillance System (HDSS) in León, Nicaragua and to present results from the 2002-2003 baseline. Design and methods: A 22\% sample of the total population in León, both urban and rural, was selected in 1993. This sample was updated in 2002 and will be followed up on a biannual basis with regard to births, deaths, in-migration, and out-migration. A group of 18 female fieldworkers perform 10 household interviews per day, 20 days per month. They use a map that is produced by a Geographical Information System. It shows all the households, and is the main means of the interviewers finding the households. An extensive data quality control system is used. Results: In total, 54,647 persons lived in the area of the surveillance system, and they resided in 10,994 households. The mean age was 26 years; the sex ratio was 0.93 . The infant and neonatal mortality rates were 25.4 and 20.5 per 1,000 live births, respectively. In total, 2,034 people out-migrated from the study area and 3,377 in-migrated. Of the households, 53\% were classified as non-poor, $41 \%$ as poor, and $6 \%$ as extremely poor. Six per cent of the population did not have a toilet or a latrine, and only $16 \%$ in the rural area had indoor running water. The surveillance system revealed that $10 \%$ were illiterate. Conclusions: The HDSS in León has shown that it can serve as a platform for further intervention studies as well as for research training.
\end{abstract}

Key Words: Demographic surveillance system, epidemiology, Nicaragua

\section{Introduction}

The Health and Demographic Surveillance System (HDSS) in Leòn (HDSS-Leòn) is the first surveillance site in Latin America to belong to the INDEPTH network (http://www.indepth-network.org/), which otherwise has most of its member sites in Africa and Asia. In Central America, the INCAP site in Guatemala has previously provided important knowledge on nutrition-infection interactions [1]. HDSS-León provides the cornerstone for activities in Centro de Investigación en Demografía y Salud (CIDS) (Demographic and Health Research Center) such as education, research, and training, and supports the local health services. This means that longitudinal data produced by the HDSS will constitute a platform for research, serving as a sampling frame for sub-studies in a wide range of areas such as health, demography, and geography. The database is also used as a source for training material within each course in the masters programme in epidemiology, as well as in short courses and the specially designed training courses for health service personnel.

The health services will be able to use the HDSS as a local planning instrument and monitoring system for specified vital statistics and diseases. Furthermore, it can be used for monitoring the impact of ongoing health and social reforms in the country. Also, the development of the CIDS with its close cooperation with the local health services will

Correspondence: Rodolfo Peña, Demographic and Health Research Center, CIDS, León University, Parque la Merced 50 m Oeste, León, Nicaragua. Tel: +505311 0368. Fax: +5053110368. E-mail: rodolfo.pena@epiph.umu.se

(Accepted 22 fune 2007)

(C) 2008 the Nordic Societies of Public Health

DOI: $10.1177 / 1403494807085357$ 
provide vast opportunities for training and mutual project work, and moreover develop local capacity in the prevention and control of disease. It will also be a useful tool when organizing studies on health programme coverage, e.g. the antenatal care services for pregnant women, vaccines for children, and services for chronic patients; moreover, the system can supply information on infectious diseases cases that can be used to validate the official statistics from the health system as well as for local planning purposes. The surveillance system will also create a unique opportunity for the development of research intervention strategies for various public health problems, such as malaria, dengue, sexually transmitted diseases, HIV/AIDS, and antibiotic resistance among children aged 3-10 years.

No systematically organized monitoring system of health development exists in Nicaragua. Like many developing countries, Nicaragua has experienced problems linked to the lack of appropriate data and information on the community level for policymakers and health managers [2].

Since 1991, the Reproductive and Child Health Project has been ongoing, with the financial support of the Department for Research Cooperation at the Swedish Agency for International Development Cooperation (SAREC, SIDA). The longstanding collaboration between the Department of Preventive Medicine, León University, Nicaragua and the Division of Epidemiology, Department of Public Health and Clinical Medicine, Umeå University led to the two extensive household surveys in 1993 and 1996 in the municipality of León (Figure 1). From these two crosssectional surveys, an epidemiological database has been created, which has enabled studies of reproductive events and child mortality over three decades using a retrospective cohort design (applying the Lexis technique from 1964 to 1993). In a 50-cluster sample of the community, covering both urban and rural areas, 7,789 households were included (Figure 1).

The database has been used in interdisciplinary and multidisciplinary studies on fertility, and for monitoring trends and investigating social determinants of infant mortality $[3,4]$. The database was also utilized in various sub-studies on teenage sexuality and reproduction, sexual risk behaviour, domestic violence, and impact of women's access and control over resources on child survival [5-14]. The database has also been used as a sampling frame for other research projects at the Medical Faculty in León, e.g. for studies of injuries in the community [15].

Thus, this experience shows that HDSS-León is an effective tool for studying the public health consequences of rapid social change and can provide a favourable research infrastructure for groups of researchers and students. As a result, CIDS was established in 2002, and was to house and administer the development of a surveillance system for the León, Nicaragua area.

An update of the database was performed in 2002-2003, when it acquired its present name of HDSS-León. It offers the opportunity to develop a model for continuous surveillance of demographic events: registering births, deaths and migration in both urban and rural areas of the municipality of León, constituting a platform for epidemiological studies. Apart from educational purposes, the database will serve as an instrument with which to evaluate applied social policies and healthcare planning.

\section{The field setting}

Nicaragua is a country with a population of five million inhabitants (2002), and is considered to be one of the poorest countries in Latin America [16]; approximately half of the population is poor, and about $17 \%$ live in extreme poverty. The poverty in Nicaragua is more profound in the rural areas, where $70 \%$ of the population are poor, in contrast to $30 \%$ in the urban areas. Almost one-third of the women report that they are victims of physical abuse when their children are present and during pregnancy. About $20 \%$ of children below 5 years of age have nutritional problems, and in $36 \%$ of the families that live in extreme poverty, there are high levels of infant and maternal mortality [17].

The effects of war, natural disasters and, first and foremost, a political failure in not directing resources to the needs of the population lead to diminished possibilities to enhance the health of the population [18]. Although the poverty problems of the country prevail, there has been an improving trend in the measures of infant mortality and in under- 5 mortality, which diminished by $20 \%$ during the period 1993-98. Better basic health services and access to primary education, especially in the rural areas, has led to a lower total fertility rate; six children per woman in 1998 changed to 5.3 in 2001 [18].

Almost $50 \%$ of the population are below 15 years of age. Sixty per cent are urban. About $25 \%$ are illiterate [19]. Two of the main income sources are agriculture and livestock breeding. This work varies according to the season; thus, most activity takes place in winter (May-October), and less in summer (November-April).

The municipality of León has an area of $820 \mathrm{~km}^{2}$. It is the second largest city of Nicaragua and a university city. León municipality is located within $90 \mathrm{~km}$ of the capital Managua. The population is estimated to be 176,915 (2002) [20]. The health system is organized on two levels: primary healthcare 

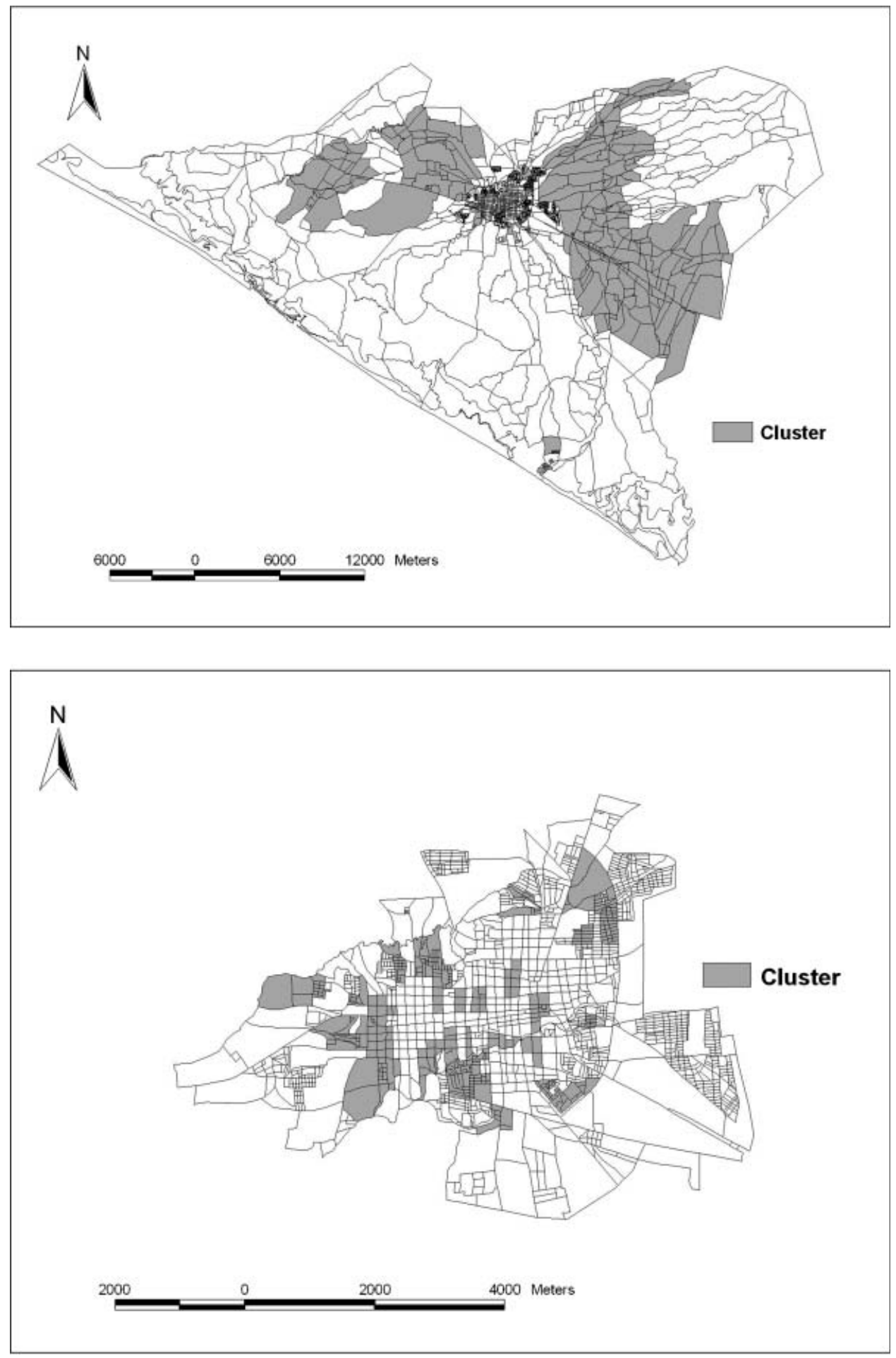

Figure 1. Maps of rural (top map) and urban areas (below map) of the Health and Demographic Surveillance System in León.

is provided by "health posts" serving a population of about 30,000, and secondary-level care is provided mainly by the regional hospital.

The aim of the present study is to describe HDSSLeón and to present some results from the 20022003 baseline.

\section{Design and methods}

The sample size created in 1993 was based on the estimated infant mortality rate of 40 per 1,000 live born, as the aim at that time was to assess the infant mortality rate. Municipal population 
statistics, validated by other local sources, were used to divide the area into 208 geographical clusters of similar population size. Of those, 50 clusters were randomly selected with probability proportional to the number of inhabitants in each cluster. A household was defined as all persons sleeping under the same roof for at least half of the past month. Maps of the study areas were prepared, and all houses in the selected clusters were enumerated. All members of the household received additional unique ID numbers as participants in the survey. In $2 \%$ of the households, the residents declined to take part in the study. A $22 \%$ sample of the total population in León municipality was selected in 1993 (195,000 inhabitants), and approximately 8,000 households were included in the sample, resulting in a population of 45,000 inhabitants.

In 2002 this 1993 database was updated, meaning that all the households were revisited, and events such as migration, deaths, births and obstetric histories from women of reproductive age were collected. These data will be followed up on a biannual basis (Table I).

In order to complete biannual rounds, a group of 18 female fieldworkers each perform approximately 10 household interviews per day, 20 days per month.

\section{Definition of variables}

Out-migration was defined as a person not living in the household for the last 6 months, and inmigration was defined as a person coming into the household and staying there for the last 6 months.

Household conditions were characterized by information on the structure of walls, floors and roofs, the type of water supply, and the use of a toilet/latrine.

Poverty was defined using a poverty index estimating the socioeconomic state. We used the
Unsatisfied Basic Needs Assessment, developed for and adapted to Nicaraguan conditions [21,22]. This measure includes four indicators: (1) housing considered to be inadequate if the house had a dirt floor or if the walls had been constructed with materials other than cement; (2) low school enrolment if there was a child of school age without education in the household; (3) highly dependent economy is built on the ratio between working and non-working persons in the household and the level of education of the head of the household; and (4) sanitary conditions as inadequate if no piped water was available inside or outside the house or if there was no flush toilet. Finally, these four indicators were added together to build the poverty index from 0 to 4 , where $0-1$ was interpreted as a non-poor household, 2-3 as a poor household, and 4 as extremely poor.

\section{Personnel and field organization}

Fieldworkers are recruited using a list of selection criteria found to be important in the León setting. Among these criteria are: being female (females were used because of the collection of sensitive obstetric histories), being unemployed, having experience in the health sector and/or working with the community, and having at least secondary school education. This is important in order to minimize information bias. Interviews are performed with the applicants, and those selected for fieldwork receive intensive applied training, usually lasting for 2-3 weeks. The focus in training is on how to conduct interviews, and discuss different concerns that may arise in that situation. During this period, at least one or two piloting exercises are performed.

A map was produced by the use of a Geographical Information System, and this map was built by taking four reference points for each block during

Table I. Examples of major information collected in the continuous monitoring system in the municipality of León, Nicaragua. Households are visited once every 6 months.

\begin{tabular}{lccc}
\hline Type of information & Unit for data collection & Time for first collection of information & Comment \\
\hline Type of house & Household & Baseline or at in-migration & Building, water, hygiene \\
Household poverty & Household & Baseline or at in-migration & A set of indicators \\
Position in household & Individual & Baseline or at in-migration & \\
Education & Individual & Baseline or at five years & \\
Occupation & Individual & Baseline or at five years & Day/Month/Year \\
Date of birth & Individual & Baseline or at birth & Day/Month/Year \\
Date of death & Individual & At death & Verbal autopsy \\
Cause of death & Individual & At death & Day/Month/Year \\
In-migration & Individual & At in-migration & Day/Month/Year \\
Out-migration & Individual & At out-migration & \\
\hline
\end{tabular}

${ }^{\mathrm{a}} \mathrm{A}$ household is composed of a group of persons who have lived together under the same roof for the previous month. ${ }^{\mathrm{b}}$ The verbal autopsy procedure is to be developed on the basis of the 1996 survey forms on cause of death. 
the 2002 updating period. This map shows all the households and is the main means for the interviewers to find the households. The Geographical Information System could also be used for spatial analyses and for intervention studies. A radio communication system is used during the datacollection periods. It provides a helpful support for the fieldwork as well as for data quality control. Coordination of transport is one of the main concerns during periods of data collection, and the availability of permanent vehicles facilitates the organization of the data collection.

\section{Data quality control system}

Three different teams of enumerators perform the fieldwork, one for each territory (Perla, Mantica, and Sutiava), and each team has a supervisor. The trained fieldworkers collect the household information on a daily basis, and at the end of each day give the questionnaires to the team supervisor. Before handing over the forms to the team leader (supervisor in the field), the fieldworker has to check them carefully. The collected questionnaires are then reviewed by the team leaders during the late afternoon before being forwarded to the so-called "filter group" (supervisor of quality control). Usually, between 100 and 120 forms are revised every day. The filter group consists of three persons who, in their turn, examine every form again, before finally delivering them to the computer staff, who enter the data into the database. Any doubtful or erroneous questionnaire is sent back to the fieldworker concerned for corrections.

An ongoing and persistent effort is focused on the internal validation of the data. Daily check-up interviews are performed by the team supervisors and by the filter group. Each fieldworker keeps a logbook, noting all errors. Weekly meetings are organized with all the staff to discuss these logbooks. The meetings help everybody to maintain high standards in their work, and avoid carelessness in filling in the forms. In this process, it is especially important that data-entry staff and researchers using the data collected meet with the fieldworkers to share their experiences. Such meetings increase the understanding of working conditions between the different staff categories (Figure 2).

A random field control exercise is performed every week. For each fieldworker, one or two questionnaires are selected randomly, and a person from the filter group or one of the researchers goes to the selected households to re-collect information, which is then compared with the original answers. The field supervisors collect all the forms on a daily basis and

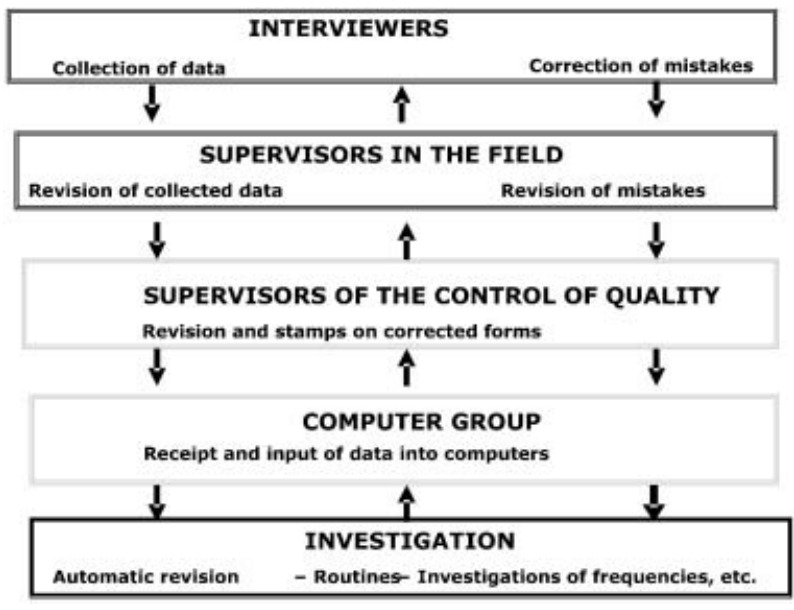

Figure 2. Data quality control system.

bring them to the CIDS office in León, where the data entry takes place. Data entry consists of a series of logical checks and cross-checks built into the data-entry program. These cross-checking routines have been developed to, for instance, detect duplicated forms. Technical support, in order to adapt the 1993 cross-sectional database into a continuous surveillance system, was obtained by collaborating with institutions with long experience of running these kinds of system. Local experts from CIDS will, together with colleagues from INDEPTH, continue to collaborate on exchanging further technical assistance and sharing experience in the development and maintenance of the database.

\section{Ethical considerations}

The protocol for HDSS-León has received ethical clearance from the ethical committees at León University (FWA00004523). In addition, the objectives of the surveillance system have been described and discussed in numerous meetings with local organizations and local authorities to obtain their acceptance and hear their considerations and/or objections, and these are taken into account. These local organizations expressed interest in interventions following the collection of data.

\section{Results}

In total, 54,647 persons live in the area of the updated and enlarged surveillance system, comprising $30 \%$ of the total population, who reside in 10,994 households. The updated database included all old clusters and new study areas in the rural zone. The non-response rate was below $1 \%$ (21 
households). In the database, $70 \%$ are urban inhabitants and $30 \%$ are rural inhabitants. The mean age is 26 years; the sex ratio is 0.93 . Women of reproductive age (15-49 years) represent $28 \%$ of the population.

The distribution per age and sex in the area are shown in a population pyramid (Figure 3 ) that is typical for communities in the developing world with a broad base that reduces as the ages increase. The group of the population between 0-9 years of age is smaller than the group that is 10 years of age or more.

We registered 1,034 live-born babies, six stillborns, and 99 spontaneous abortions. The infant mortality rate was 25.4 per 1,000 live births and the neonatal mortality rate was 20.5 per 1,000 live births. The trend in child, infant and neonatal mortality is shown in Figure 4. The average number of children at the end of women's fertile life was five.

In the baseline, we found 2,034 people who outmigrated from the study area, $88 \%$ of whom were urban dwellers, and 3,377 who in-migrated to the study area.

Six per cent of the population does not have a toilet or a latrine, and whereas $96 \%$ of the households in the urban area have access to running water in their houses, only $16 \%$ in the rural area have running water indoors.

Of the 10,994 households, $53 \%$ were classified as non-poor, $41 \%$ as poor, and $6 \%$ as extremely poor (Table II).

In the area of the surveillance system, $10 \%$ were illiterate, $20 \%$ in the rural area and $6 \%$ in the urban area.

\section{Connected studies}

There are several sub-studies connected with HDSS-León. These include one on attempted suicide among adolescents, in which a subsample of 352 adolescents was interviewed [23]. Another deals with partner violence towards pregnant women; 478 pregnant women were followed and studied for exposure to partner violence and its impact on child outcomes [24]. The principal criticisms of epidemiological studies of functional gastrointestinal disorders, including irritable bowel syndrome and functional dyspepsia,

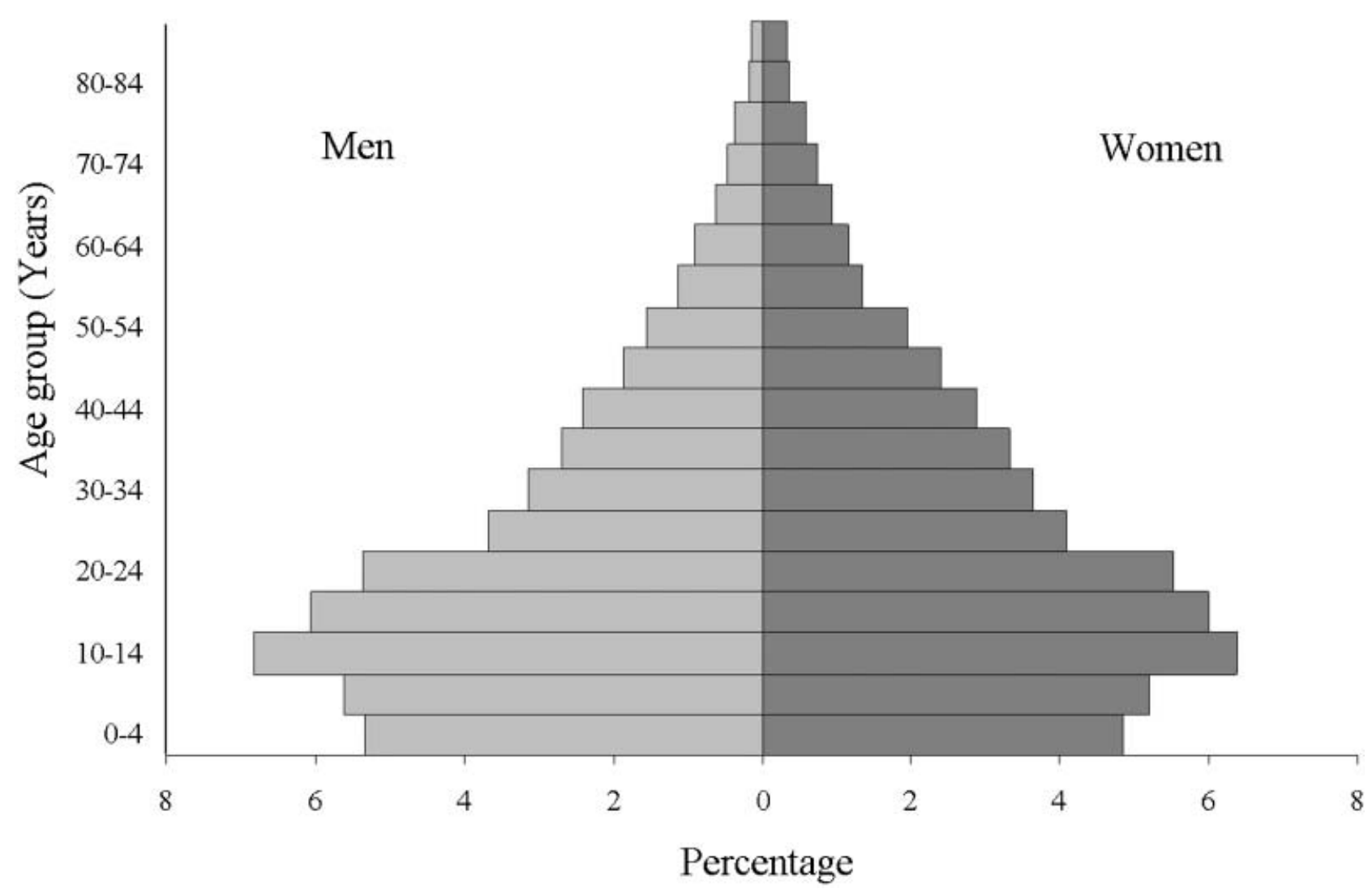

Figure 3. Population pyramid in the León area of the surveillance system, 2002. 


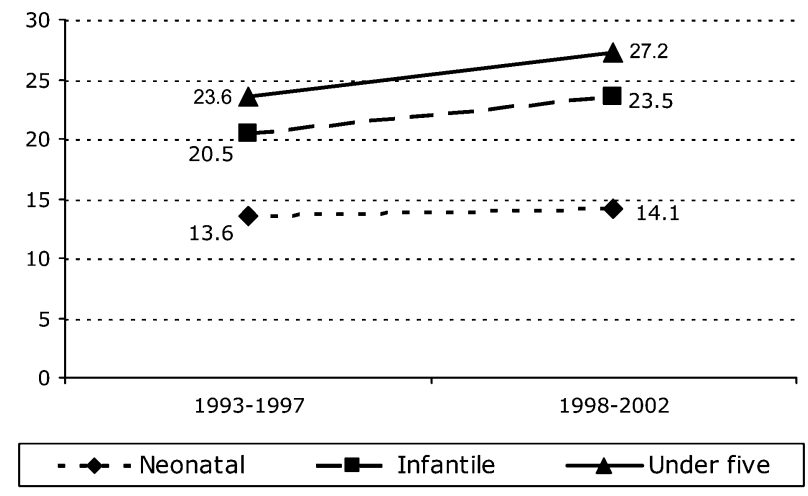

Figure 4. Child mortality trends per 1,000 live births, 1993-2002.

include the lack of population-based studies, and underrepresentation of the Hispanic population in the Americas. Thus, in the beginning of 2004, 2,500 subjects were interviewed using the Roma II instrument for functional gastrointestinal disorders [25]. Laboratory data from hospitals and outpatient services do not adequately reflect problems in the general population, especially with regard to infectious diseases such as diarrhoea in children. Based on the ongoing community surveillance system, a sample of 600 children was followed by home visits over two 13-week periods, the first during the dry season (December-March, 2002) and the second during the rainy season (June-September, 2003). Other studies on children taking care of their siblings; and on chronic disease in adults, are ongoing.

\section{Discussion and conclusion}

The experience from the cross-sectional studies performed during the 1990 s showed that it was possible to collect and analyse valid data in the Nicaraguan urban and rural settings. This suggested the possibility of establishing a surveillance site that would serve as a platform for research into public health problems, as well as serving as a monitoring and planning tool. Furthermore, the experience showed that an epidemiological field laboratory may be an effective way of studying the public health consequences of rapid social change and can

Table II. Poverty index.

\begin{tabular}{lccc}
\hline & Total, $n(\%)$ & Rural, $n(\%)$ & Urban, $n(\%)$ \\
\hline Not poor & $5,778(52.6)$ & $1,004(30.7)$ & $4,774(61.8)$ \\
Poor & $4,507(41.0)$ & $1,935(59.2)$ & $2,572(33.3)$ \\
Extremely poor & $709(6.4)$ & $334(10.2)$ & $375(4.9)$ \\
\hline
\end{tabular}

These indices are based on unsatisfied basic needs assessment, which is explained in the text. offer a favourable research infrastructure for groups of researchers and students.

During the development of the HDSS, we have encountered the lack of a good radio communication system, especially in the rural areas, where this prolongs the data collection. We also experienced a problem with only having two persons doing the datachecking in the office, as it delayed the data entry. The computer database system was not adequately piloted, especially with regard to the logical checking and rules for validation, and this led to an unnecessarily high number of errors in the database.

Despite these problems, the surveillance system is now established and the baseline data are being analysed; we can conclude that the surveillance system is working and is being used for research and education as well as for the health services.

Finally, the results from the baseline show a population in need of many basic services. The proportion of poor people is very high, as is the rate of illiteracy, especially in the rural area. This shows that there are many basic needs not being fulfilled in Nicaraguan society. The specific findings of the narrowing population pyramid and the non-equivalent male/female ratio could be due to migration and later effects of the war period; however, these are hypotheses and need to be studied further.

\section{Acknowledgements}

Our thanks go to the people who agreed to participate and be part of the surveillance site, and the enumerators and supervisors. This study was supported by the Department for Research Cooperation at the Swedish International Development Cooperation Agency (SAREC, SIDA), Sweden.

\section{References}

[1] Instituto de Nutrición de Centroamérica y Panamá. Available at: http://www.sica.int/incap (accessed 7 February 2006).

[2] Chuk NTK, Diwan VK. FilaBavi, a demographic surveillance site, an epidemiological field laboratory in Vietnam. Scand J Public Health 2003;31(Suppl 62):3-7.

[3] Peña R, Liljestrand J, Zelaya E, Persson LÅ. Fertility and infant mortality trends in Nicaragua 1964-1993. The role of women's education. J Epidemiol Community Health 1999;53:132-7.

[4] Peña R, Wall S, Persson LÅ. The effect of poverty, social inequity, and maternal education on infant mortality in Nicaragua 1988-1993. Am J Public Health 2000;90:64-9.

[5] Berglund S, Liljestrand J, Marin F, Salgado N, Zelaya E. The background of adolescent pregnancies in Nicaragua. Soc Sci Med 1997;44:1-12.

[6] Zelaya E, Marín FM, García J, Berglund S, Liljestrand J, Persson LA. Gender and social differences in adolescent 
sexuality and reproduction in Nicaragua. J Adolesc Health 1997;21:39-46.

[7] Zelaya E, Peña R, García J, Berglund S, Liljestrand J, Persson LA. Contraceptive patterns among women and men in León, Nicaragua. Contraception 1996;54:359-65.

[8] Ellsberg M, Caldera T, Herrera A, Winkvist A, Kullgren G. Domestic violence and emotional distress among Nicaraguan women. Results from a population-based study. Am Psychologist 1999;54:30-6.

[9] Ellsberg M, Peña R, Herrera A, Liljestrand J, Winkvist A. Candies in hell: Women's experiences of violence in Nicaragua. Soc Sci Med 2000;51:1595-610.

[10] Åsling Monemi K, Peña R, Ellsberg M, Persson LÅ. Violence against women increases the risk of infant and child mortality. A case-referent study in Nicaragua. Bull World Health Organ 2003;81:1-18.

[11] Valladares E, Ellsberg M, Peña R, Högberg U, Persson LA. Physical partner abuse during pregnancy: a risk factor for low birth weight in Nicaragua. Obstet Gynecol 2002;100:700-5.

[12] Ellsberg M, Heise L, Peña R, Agurto S, Winkvist A. Researching domestic violence against women: methodological and ethical considerations. Studies Fam Planning 2001;32:1-16.

[13] Olsson A, Ellsberg M, Berglund S, Herrera A, Zelaya E, Peña $R$, et al. Sexual abuse during childhood and adolescence among Nicaraguan men and women. A populationbased anonymous study. Child Abuse Neglect 2000;24: 1579-89.

[14] Ellsberg M, Winkvist A, Peña R, Stenlund H. Women's strategic responses to violence in Nicaragua. J Epidemiol Community Health 2001;55:547-55.

[15] Terceo F, Andersson R, Peña R, Rocha J, Castro N. The epidemiology of moderate and severe injuries in a Nicaraguan community: a household-based survey. Public Health 2006;120:106-14.
[16] World Bank. Nicaragua. Poverty assessment. Raising welfare and reducing vulnerability. Report No.26128-NI. 23 December 2003.

[17] Scrimshaw NS. Synergism of malnutrition and infection. Evidence from field studies in Guatemala. JAMA 1970;212: 1685-92.

[18] Birn AE, Zimmerman S, Garfield R. To decentralize or not to decentralize, is that the question? Nicaraguan health policy under structural adjustment in the 1990s. Int J Health Serv 2000;30:111-28.

[19] Instituto Nacional de Estadísticas y Censos. Nicaragua. Available at: www.inec.gob.ni.

[20] Instituto Nicaragüense de Estadísticas y Censos. Estimaciones y Proyecciones de la población total por año calendario, según departmento y municipio período 20002005. Managua: INEC; 2004. Available at www.inec.gob.ni (accessed 27 March 2006).

[21] Renzi MR, Agurto S. Siuacíon econoómca y social de León, Managua y Granada. Managua, Nicaragua. Managua: Fundación Internacinal para Desafio Económica Global, FIDEG; 1993.

[22] Renzi MR, Agurto S. Mercado laboral y condiciones de vida de la población urbana de Managua, León y Granada. Managua: Fundación Internacinal para Desafio Económica Global, FIDEG; 1993.

[23] Herrera A, Caldera T, Kullgren G, Rengberg E. Suicidal expressions among young people in Nicaragua. A community -based study. Soc Psychiatry Psychiatr 2006;41:692-7.

[24] Valladares E, Peña R, Persson LÅ, Högberg U. Violence against pregnant women: prevalence and characteristics. A population-based study in Nicaragua. Br J Obstet Gynaecol 2005;112:1243-8.

[25] Drossman DA, editor. Rome II. The functional gastrointestinal disorders, 2nd edn. McLean VA: Degnon Associates; 2000. p 669-88. 